\title{
Rabiscos e Emoções: Nova Perspectiva sobre o Desenvolvimento do Desenho
}

\author{
Evelyn de Oliveira ${ }^{1}$, Sonia Grubits \\ Universidade Católica Dom Bosco - UCDB, Campo Grande-MS, Brasil
}

\section{RESUMO}

O desenho é uma forma de expressão que vai muito além do lápis e papel. Muitos artefatos e materiais foram utilizados pelo homem ao longo do tempo para registrar sua história. Por meio de pesquisa bibliográfica, objetivou-se, com o presente trabalho, apresentar uma nova teoria sobre o desenho infantil, denominada como Perspectiva Dinâmica e Estética. Essa perspectiva divide o desenvolvimento do grafismo infantil em estágios, como as teorias clássicas, mas se diferencia delas quando propõe que a expressão de estados emocionais, por meio do rabisco da criança, já é possível por volta dos dois-três anos de idade, na fase chamada rabisco expressivo. O rabisco é mais que a consequência do gesto, não é motivado somente pelo prazer motor e parece ser capaz de expressar estados emocionais. A Perspectiva Dinâmica e Estética integra funcionalmente aspectos biológicos, psicológicos e sociais na descrição de um processo fluído na evolução do desenho.

Palavras-chave: Desenvolvimento humano; Infância; Psicologia; Grafismo; Desenho infantil.

\section{ABSTRACT - Scribbles and emotions: a new perspective on the development of drawing}

Drawing is a form of expression that goes far beyond pencil and paper. Many artifacts and materials have been used by man over time to record our history. By means of a bibliographical study, the aim of this work was to present a new theory about childish drawing called the Dynamic and Aesthetic Perspective. This perspective divides the development of childish drawing into stages, in the same way as the classical theories, however, differs from them when it proposes that the expression of emotional states through the child's scribble is already possible at around 2-3 years of age, in the phase called expressive scribbling. The scribble is more than the gesture's consequence; it is not motivated solely by motor pleasure and seems to be able to express emotional states. The Dynamic and Aesthetic Perspective functionally integrates biological, psychological, and social aspects into the description of a fluid process in the evolution of the drawing.

Keywords: Human development; Childhood; Psychology; Graphical stages; Childish drawing.

\section{RESUMEN - Garabatos y emociones: una nueva perspectiva sobre el desarrollo del dibujo}

El dibujo es una forma de expresión que va mucho más allá del lápiz y el papel. Muchos artefactos y materiales fueron utilizados por el hombre a lo largo del tiempo para registrar su historia. Son el presente trabajo se objetivó, por medio de investigación bibliográfica, presentar una nueva teoría sobre el dibujo infantil denominada Perspectiva Dinámica y Estética. Esta perspectiva divide el desarrollo de la expresión gráfica infantil en etapas, como las teorías clásicas, pero se diferencia de ellas cuando propone que la expresión de estados emocionales, a través del garabato de los niños, ya es posible alrededor de los dos-tres años, en la fase denominada como garabato expresivo. El garabato es más que la consecuencia del gesto, no es motivado solamente por el placer motor y parece ser capaz de expresar estados emocionales. La Perspectiva Dinámica y Estética integra funcionalmente aspectos biológicos, psicológicos y sociales en la descripción de un proceso fluido en la evolución del dibujo.

Palabras clave: Desarrollo humano; Infancia; Psicología; Expresión gráfica; Dibujo infantil.

O desenho é tema de amplo interesse na Psicologia. Inicialmente, foi utilizado como forma de medir a capacidade cognitiva em estruturação de testes de inteligência e, posteriormente, reconhecido como importante recurso projetivo, dando origem a testes de personalidade. Atualmente, os testes com base em desenhos são amplamente utilizados no contexto da avaliação psicológica e podem, também, especialmente no caso de crianças, ser utilizados no contexto psicoterapêutico como meio facilitador do estabelecimento do vínculo.
A Psicologia apresenta inúmeras formas de conceber o desenho infantil. Os testes de desenho despertam peculiar interesse dos pesquisadores, em especial o Desenho da Figura Humana, que pode fornecer componentes cognitivos e indicadores de criatividade, embora originalmente o instrumento fosse utilizado para avaliar a cognição (Oliveira \& Wechsler, 2016).

A utilização do desenho como recurso de pesquisa em ambiente hospitalar é uma estratégia largamente utilizada por psicólogos. Por exemplo, a preparação 
psicológica pré-cirúrgica de crianças por meio de atividades de produção gráfica resulta em minimização dos sentimentos de desconforto (Broering \& Crepaldi, 2014).

A efetividade do desenho infantil como modo de produção de sentidos na construção do conhecimento também foi investigada no Brasil (Silva, Aguiar Jr., \& Belmiro, 2015). Os resultados apontaram que o desenho é potencialmente expressivo e comunicativo para o processo de construção de conceitos científicos. No México, o desenho foi utilizado com crianças e adolescentes de uma escola rural com o objetivo de avaliar os valores e os conhecimentos das crianças sobre a água (Schwarz, Herrmann, Torri, \& Goldberg, 2016).

A inter-relação da atividade simbólica de desenhar com o desenvolvimento de linguagem de crianças surdas foi tema de trabalho realizado por Zerbato e Lacerda (2015). Examinaram voluntários de quatro a sete anos de idade, concluindo que, assim como a linguagem de sinais, o desenho contribui para o progresso linguístico e cognitivo.

O desenho, seguido de entrevista, foi utilizado para investigar o significado atribuído à alimentação escolar com crianças de primeiro ao quarto ano de escolas públicas. Concluiu-se que as crianças associavam à hora da alimentação, além da relação com os alimentos, também o ambiente escolar e a interação com os pares (Assao, Westphal, Bógus, Lara, \& Cervato-Mancuso, 2014).

No contexto da educação, o desenho também é utilizado como recurso metodológico em pesquisas, além de ser considerado como instrumento facilitador da construção do conhecimento. "Alunos de ambos os sexos e de qualquer classe social, acompanhados de professores que promovem atividades com garatujas, estão, com certeza, possibilitando o desenvolvimento da escrita com maior facilidade" (Federizzi \& Cunha, 2015, p. 95).

A versatilidade na utilização do desenho como objeto de estudo e como procedimento metodológico é evidente em diferentes campos de pesquisa. Observase, contudo, que as pesquisas se concentram em participantes na idade escolar. A fase das garatujas não parece despertar questionamentos ou interesse tão acentuado na literatura científica.

Frente a esse contexto, objetivou-se com o presente trabalho, apresentar resultados de pesquisa bibliográfica pautada nos termos "desenho infantil", "children's drawings", "garatujas" e "scribbling" como palavras-chave, nas bases de dados SciELO, BVS-PSI, Google acadêmico, Science Direct e PubMed, apreendendo os artigos publicados no período de 2014 a 2018. Com base nos achados, pretende-se apresentar informações adicionais sobre uma nova teoria sobre o desenho infantil, denominada "Perspectiva Dinâmica e Estética do desenho", de modo a embasar novas possibilidades analíticas e interpretativas da produção gráfica infantil. $\mathrm{Na}$ estruturação deste artigo, inicialmente serão apresentadas contribuições das teorias clássicas sobre o desenho infantil, posteriormente, contextualizando a Perspectiva Dinâmica e Estética, desde o estágio do rabisco.

\section{A Evolução do Desenho Infantil segundo Teorias Clássicas}

Historicamente o estudo do desenho se iniciou com Corrado Ricci, por volta de 1880 (Campos, 1987; Cox, 2012). O desenho é uma forma de expressão que vai muito além do lápis e papel. Muitos artefatos e materiais foram utilizados pelo homem ao longo do tempo para registrar sua história (Derdyk, 2015). O desenho pode ser considerado universal, e comunicar-se por meio dele é uma das formas mais antigas e permanentes utilizada pelo homem (Derdyk, 2015; Lopes, 2012).

Desenhar é um ato espontâneo adquirido pelo homem durante seu desenvolvimento e é na infância que o desenho apresenta seus primeiros traços de expressão e comunicação. Os desenhos do adulto e da criança não são herméticos. Os dois compõem o universo humano de construção do conhecimento, afetando-se mutuamente (Derdyk, 2015). Contudo, enquanto o desenhar adulto se concentra no produto final, a criança, quando desenha, está focada no processo, na experiência da criação (Bombonato \& Farago, 2016; Lowenfeld, 1970).

A criança desenha para se divertir (Derdyk, 2015; Luquet, 1969) e, ao fazer isso, dá vasão a sua capacidade criativa. O desenho é uma forma de expressão democrática, desenvolvida por crianças de diferentes etnias, credos e classes sociais. Ela traduz no desenho aquilo que não pode expressar de outra forma.

A criança manifesta sua integralidade quando desenha. Derdyk (2015) comenta que:

"O desenho constitui para a criança uma atividade total, englobando o conjunto de suas potencialidades e necessidades. Ao desenhar, a criança expressa a maneira pela qual sente o existir. O desenvolvimento do potencial criativo na criança, seja qual for o tipo de atividade em que ela se expresse, é essencial ao seu ciclo inato de crescimento. Similarmente, as condições para o seu pleno crescimento (emocional, psíquico, físico, cognitivo) não podem ser estáticas” (p. 57).

O contexto em que a criança vive irá influenciar sua produção artística, de modo que a totalidade da criança se evidencia também quando se encontra em seus desenhos a expressão de aspectos culturais. Méredieu (2006), ao mencionar o sofrimento de crianças argelinas, palestinas, vietnamitas e daquelas que vivenciaram a terrível experiência dos campos de concentração, afirma que as produções das crianças refletem a crueldade dos acontecimentos, pois a vivência trágica é evidenciada e faz parte do cotidiano.

Alguns estudiosos clássicos (Lowenfeld, 1970; Luquet,1969; Méredieu, 2006; Piaget, 1976) e outros contemporâneos (Quaglia, Longobardi, Iotti, \& Prino, 2015) dissertaram sobre o desenho infantil. Descreveram 
seu desenvolvimento por meio de estágios balizados pela evolução neuropsicomotora da criança.

Piaget foi um dos pioneiros a estudar manifestações artísticas das crianças por meio de um olhar científico. Ele observou que sua teoria de desenvolvimento em quatro estágios (sensorio-motor, pré-operacional, operacional concreto e operacional formal) (Piaget, 1976) poderia ser aplicado aos desenhos e que as crianças tinham um desenvolvimento quase paralelo entre seu crescimento cognitivo e suas habilidades de desenho. Anteriormente, os quatro estágios de desenho já haviam sido teorizados por Luquet, que estudou os desenhos de sua filha e os classificou em quatro estágios: Realismo Casual, Realismo Perdido, Realismo Intelectual e Realismo Visual (Bombonato \& Farago, 2016; Luquet, 1969).

$\mathrm{Na}$ perspectiva realista de Luquet (Bombonato \& Farago, 2016; Luquet, 1969) acreditava-se que a atividade gráfica evoluía gradualmente, seguindo de um simples exercício para uma forma de jogo estruturado. Para o autor, os traços gráficos surgiam espontaneamente, mas eram suscetíveis a influências dos adultos. A passagem do rabiscar, como simples atividade motora, para rabiscos controlados e, posteriormente, para o desenho real, com um propósito representativo, acontecia espontaneamente.

Uma perspectiva artística do desenho infantil foi forjada por Lowenfeld (1970). Para o autor, o desenvolvimento geral das crianças estava relacionado com seu desenvolvimento criativo. Há uma passagem de "o que" as crianças estão desenhando para "como" elas estão desenhando na abordagem artística, isto é, atém-se aos recursos elaborados durante o ato da criação. Nessa perspectiva, o objeto do estudo muda das produções gráficas aos processos mentais ativados pelas crianças, com o objetivo de adquirir uma compreensão mais profunda desse último.

Lowenfeld (Lowenfeld, 1970) dividiu o desenvolvimento do grafismo infantil em fase das garatujas, subdivida nos estágios de rabiscos desorganizados (não possui controle visual) e rabiscos controlados (existe uma relação entre movimentos e traços), fase pré-esquemática, fase esquemático e fase do realismo $O$ prazer deixa de ser motor e é proporcionado pela consciência de ser a causa de um movimento e o autor de um produto. Quando as crianças dão um nome a um rabisco, elas evoluem de uma mentalidade cinestésica para uma imaginativa (Bombonato \& Farago, 2016; Federizzi \& Cunha, 2015).

A perspectiva artística, assim como a perspectiva realista, considera o prazer que as crianças experimentam ao desenhar, contudo não há mais somente o prazer na atividade motora, há também prazer estético, que não está vinculado a qualquer intenção representativa.

As perspectivas dinâmica e estética, assim como as teorias mencionadas anteriormente, também dividem o desenvolvimento do grafismo infantil em estágios sendo eles: estágio do Rabisco (imitativo e expressivo),
Esteticismo moral (primário e secundário), Rabiscos onomatopeicos, Rabiscos figurativos, Esteticismo prático e Esteticismo convencional (Quaglia et al., 2015).

A diferença fundamental entre as perspectivas anteriores e a Perspectiva Dinâmica e Estética é a ênfase dada ao estudo das fases do rabisco que, embora sejam sempre mencionadas nas teorias clássicas, não receberam a atenção devida por serem consideradas como simples consequências do gesto e motivadas pelo prazer motor. De acordo com a Perspectiva Dinâmica e Estética, na segunda fase do estágio do rabisco, chamada de Rabisco Expressivo (por volta dos dois-três anos de idade) as linhas expressam estados emocionais e não são sustentadas somente pelo prazer motor ou pelo produto visualizado pela criança (Longobardi, Pasta, \& Quaglia, 2012; Longobardi, Quaglia, \& Iotti, 2015; Quaglia et al., 2015; Quaglia \& Saglione, 1976).

Os estados emocionais mais antigos e mais arcaicos estão ligados ao bem-estar ou ao desconforto. Os traços gráficos na fase do rabisco expressivo parecem adquirir duas formas expressivas que estão ligadas aos comportamentos emocionais de gratificação e frustração: no primeiro, há prevalência de linhas arredondadas; no último, linhas grossas e quebradas predominam. Longobardi et al. (2015) identificaram essas duas formas, respectivamente, como "traço bom" e "traço mau" e afirmam que esses tipos de rabiscos são universais e arquetípicos, embora nenhum autor até agora os tenha distinguido em "bom" e "mau". Os rabiscos expressivos não tendem a representar objetos do mundo real; mas, em vez disso, eles expressam as qualidades "boas" ou "ruins" desses objetos por meio da forma que as crianças dão às suas linhas (Longobardi et al., 2015). As crianças não desenham o que veem, elas desenham o significado afetivo que atribuem a alguma coisa.

\section{A Perspectiva Dinâmica e Estética e os Rabiscos}

A origem do rabisco é diferente para cada criança e, embora pareça algo descoberto casualmente, é um processo esperado. Diante disso, o incomum seria a criança que não desenha, e não a que desenha. As crianças que não desenham são aquelas que: ou não tiveram a oportunidade de verem os pais escreverem ou não receberam deles condições materiais ou reforços afetivos para desenhar. O desenho, assim como outras atividades fundamentais para o desenvolvimento da criança, evolui mais eficazmente dentro de um relacionamento emocionalmente rico. Dessa forma, assim como a linguagem, o desenho surge em uma relação gratificante com o adulto (Longobardi et al., 2012). O acolhimento do adulto frente aos primeiros rabiscos da criança servirá como fator norteador para o avanço ou estagnação no desenvolvimento dessa forma de expressão.

No começo, a criança imita o gesto do adulto que escreve, mais tarde ela descobre o interesse por sua própria produção. Essa etapa ocorrerá caso haja a expressão de 
interesse dos adultos pelo desenho da criança. "Nenhum aprendizado acontece por acaso e toda alegria autêntica da criança é expressa dentro do diálogo relacional com os pais. Não há prazer que possa surgir e ser nutrido no vazio emocional" (Longobardi et al., 2012, p. 60).

$\mathrm{Na}$ fase do rabisco imitativo (um-dois anos) ocorre a escrita do rabisco, que é quando a criança imita o adulto ao escrever, dando origem a linhas predominantemente horizontais e onduladas (Figura 1). Posteriormente, ocorrerá um novo traçado multiforme, que é o produto da descoberta da criança sobre a expressividade da linha, nomeando-se essa fase de rabisco expressivo (dois-três anos). Nessa fase, a criança manipula a linha, explorando-a e modelando-a no papel. Ela experimenta as linhas por meio do animismo infantil e a percepção dinâmica que tem da realidade. Dessa forma, a linha que escapa da folha "fugiu"; uma linha interrompida devido a quebra da ponta do lápis "está morta", uma linha desenhada rapidamente "está correndo", uma linha que é interrompida pela quebra da própria folha "caiu no buraco" (Longobardi et al., 2012; Quaglia et al., 2015).

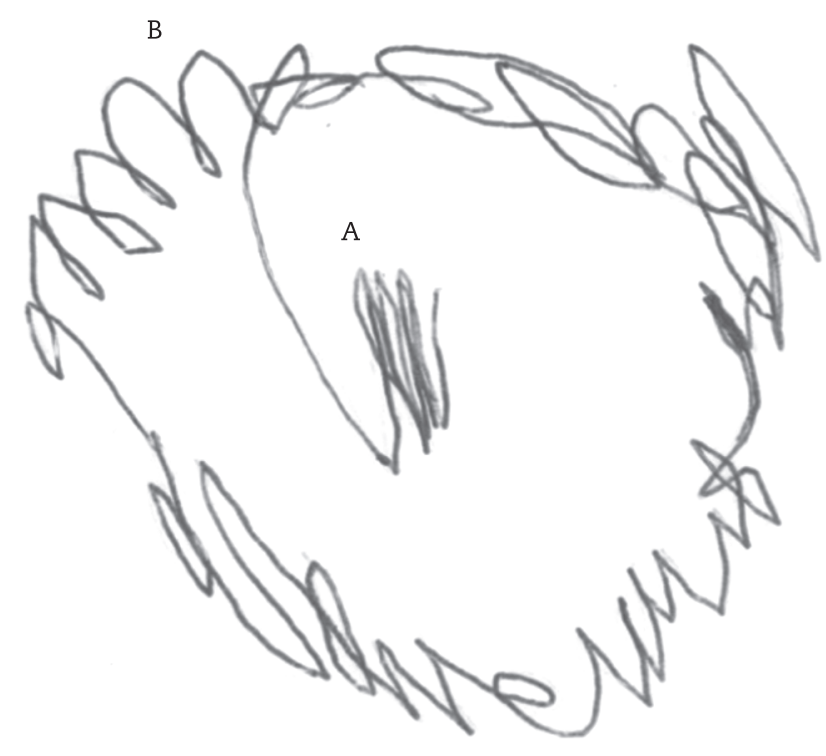

Figura 1. Anna (2 anos e 9 meses) brincando com miniaturas (Longobardi, Negro, Pagani, \& Quaglia, 2001)

A linha, independentemente do conteúdo, tem carga expressiva, vitalidade, dinâmica e forma. Ela pode ser grossa, fina, angular, espiral, horizontal, entre outros formatos. Pode, também, ter brilho, ser opaca, transparente. Na fase do rabisco expressivo, as linhas expressam estados emocionais (Longobardi et al., 2012; Quaglia et al., 2015).

Os estados emocionais mais arcaicos estão associados ao bem-estar e ao desconforto. O rabisco da criança adquire, então, duas formas expressivas relacionadas a uma atitude emocional de gratificação ou frustração e são classificadas como "traço bom" e "traço mau" (Longobardi et al., 2012; Longobardi et al., 2015; Quaglia et al., 2015).

Anna ( 2 anos e 9 meses) é uma criança que gosta de brincar com miniaturas. Em uma das pausas de suas brincadeiras, solicitaram-lhe que desenhasse a si mesma brincando. Inicialmente a criança rabiscou no centro da folha linhas verticais (Figura 1, traço A) e, em seguida, de forma confiante, a menina espaçou o traçado (Figura 1, traço B) em volta do primeiro traço. Quando questionaram sobre onde estava Anna no desenho, sem hesitar ela indicou as linhas verticais localizadas no centro da folha (Figura1, traço A). Questionada novamente quanto a: "E essas outras linhas, o que são elas?" (Figura 1, traço B) "É Anna brincando com as miniaturas" (Longobardi et al., 2001).

Em um segundo momento, solicitou-se que Anna desenhasse Enzo (colega com o qual Anna não tem afinidade). De início ela desenhou um pequeno emaranhado de linhas (Figura 2, traço A) e, mais abaixo, na folha, desenhou mais algumas linhas espalhadas (Figura 2, traço B) de forma descuidada e desatenta. Quando questionada sobre onde estava Enzo, a menina aponta para o pequeno conjunto de linhas do meio da folha. Quanto às linhas do traço $B$, Anna diz se tratar de "Enzo, que está batendo em outra criança" (Longobardi et al., 2001). 


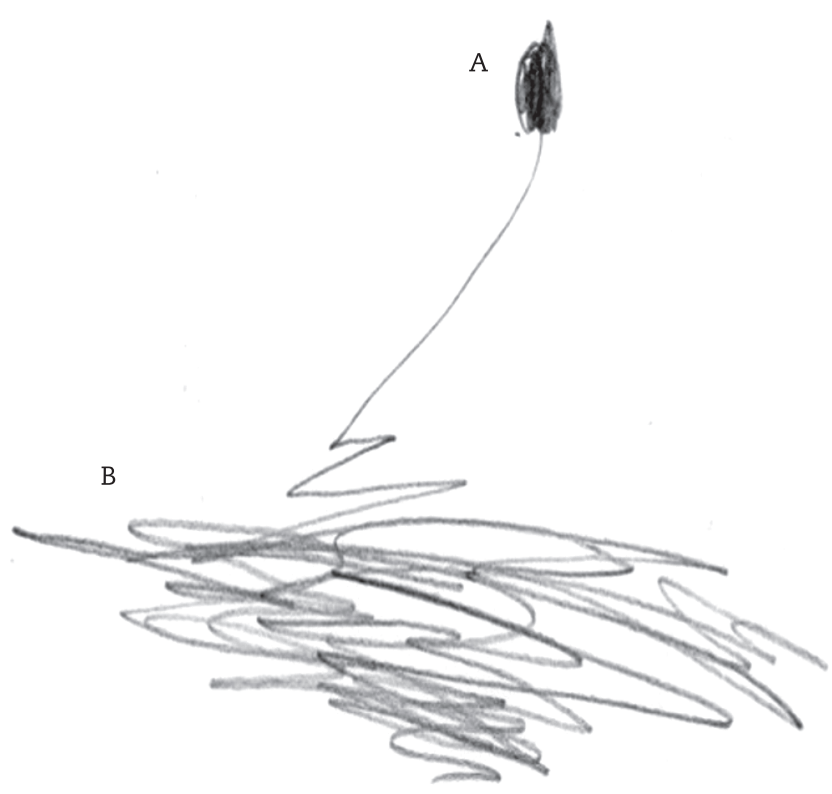

Figura 2. Anna (2 anos e 9 meses) desenhando o colega Enzo, com quem não tinha afinidade (Longobardi et al, 2001)

O primeiro desenho de Anna (Figura 1) apresenta um contorno suave e arredondado (traço bom) e revela uma atividade agradável e envolvente. Já o segundo desenho (Figura 2) apresenta linhas marcadas e angulares (traço mau), expressando uma atitude emocional de fechamento e negação em relação ao colega e a seu comportamento (Longobardi et al., 2012; Longobardi et al., 2015; Quaglia et al., 2015; Quaglia \& Saglione, 1976).

\section{Esteticismo Moral}

Concomitantemente à fase do rabisco, ocorrem, também, o estágio do Esteticismo moral primário e Esteticismo moral secundário. No primeiro (que está presente em toda fase do rabisco, de zero a cinco anos), as linhas são combinadas com o gesto do desenho e expressam suas qualidades dinâmicas, podendo ser rápidas, lentas, tristes e felizes. Dependendo de como são desenhadas, podem correr ou andar. As linhas expressam estados emocionais, como tristeza, felicidade, entre outros, porque os refletem. O segundo estágio (cinco-seis anos) marca a transição do rabisco para o desenho figurativo. Surgem os primeiros desenhos esquemáticos e as categorias de "boas" ou "más", não indicam mais as características fisionômicas da linha, mas os objetos do mundo externo. Assim, o desenho de um lobo é feio, porque ele pode ser terrível e assustador; e o desenho de uma mãe é bom, porque uma mãe pode ser boa e atenciosa (Quaglia \& Saglione, 1976).

Como exemplo de esteticismo moral primário, relata-se o caso de Stefano (dois anos e quatro meses) que, após bater a cabeça na mesa e se vingar batendo nela, fez um rabisco com linhas grossas, sobrepostas e pontudas e o chamou de "mesa feia" (Figura 3). A criança ficou satisfeita com seu desenho, o que qualificou como "feia" foi a experiência dolorosa que teve (Quaglia et al., 2015). Stefano não tinha intenção de representar a mesa na forma físico-geométrica, mas queria representar a experiência de bater naquele objeto que classificava como "mau" (Longobardi et al., 2015).

No estágio do esteticismo moral secundário, a forma gráfica é deslocada das linhas para o conteúdo. Fealdade e Beleza agora se referem às propriedades do objeto desenhado e não mais as propriedades das linhas. Se for solicitado a uma criança que desenhe algo bom, independentemente da idade, ela certamente não encontrará dificuldade em fazê-lo, contudo se for pedido que ela faça uma versão ruim ou feia do mesmo desenho, ela possivelmente terá dificuldade em realizar a tarefa antes dos seis anos. Por sua vez, as crianças de seis-sete anos compreenderão a tarefa, mas podem se recusar a executá-la, pois, nessa fase, as categorias de "bom" e "mau" são atribuídas ao conteúdo do desenho e seria incompreensível desenhar uma versão "ruim" de algo bom como uma mãe, por exemplo (Quaglia et al., 2015).

\section{Rabiscos Onomatopeicos}

A característica desses rabiscos é que, durante sua execução, eles são acompanhados por expressões onomatopeicas. $\mathrm{Na}$ forma, eles não se diferenciam dos rabiscos anteriores, mas algo muda na relação entre a criança e os objetos. A partir de seu próprio mundo interior, a criança se volta para o mundo exterior. A onomatopeia é o instrumento utilizado pela criança para representar a atividade de um objeto externo, delimitando, assim, o início do "faz de conta" (Longobardi et al., 2012). 


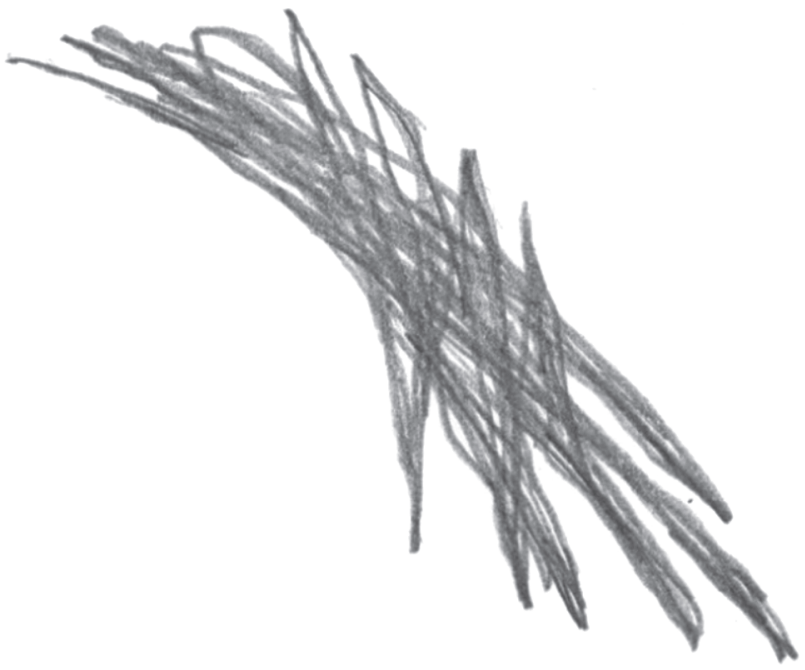

Figura 3. O desenho de Stefano que bateu a cabeça na mesa (exemplo de traço mau) (Longobardi et al., 2015)

Para exemplificar, será utilizado o desenho de Stefano (menino, dois anos e quatro meses) que, ao realizar seus primeiros rabiscos, usou-se de traços circulares que chamou de "motocicleta", acompanhados por onomatopeias "vromm, vromm", como mostra a Figura 4a-b (Quaglia \& Saglione, 1976). Não há, ainda, interesse pela representação do objeto real, pois a criança está interessada pelo o que objeto realiza e pelo que ela experiencia por meio do objeto, pois: "As crianças não vivem em um mundo estático, composto de objetos estáticos; eles vivem em um mundo dinâmico, onde objetos se movem e coisas interessantes acontecem o tempo todo" (Quaglia et al., 2015, p. 87).
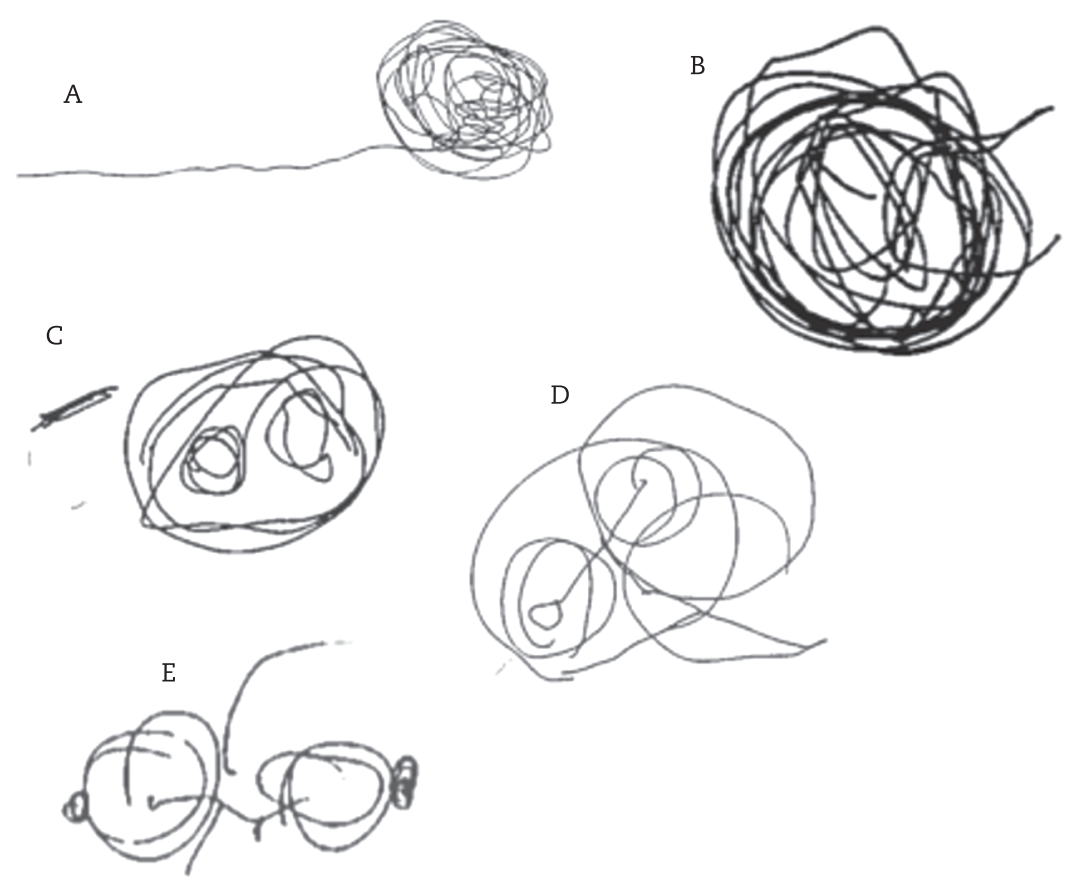

Figura 4. O desenvolvimento da moto de Stefano, desenhada em suas várias fases

Nota. (A) e (B) são exemplos de rabiscos onomatopeicos (idade dois anos e quatro meses), enquanto (C) e (D) são as primeiras tentativas de representação estrutural de uma motocicleta a partir de suas partes móveis (idade dois anos e oito meses); (e) representa a evolução final do rabisco figurativo (idade dois anos e dez meses), onde a qualidade dinâmica do objeto representado foi relegada a partes específicas (por exemplo, as rodas) (Longobardi et al., 2012). 


\section{O Desenho Figurativo}

As primeiras tentativas de desenhar um objeto geralmente se mostram por meio de rabiscos organizados no espaço, sem forma bem definida. A semelhança entre o que se desenha e o que é desenhado não é observada na perspectiva das estruturas formais, e sim de forma topográfica. Ao se observar o desenho de Stefano da "motocicleta", é possível ver formas e tamanhos variados de rabiscos que representam rodas, guidom e assento e estão organizados em uma relação espacial (Figura 4, C - E) (Longobardi et al., 2012).

As primeiras figuras pretendidas pelas crianças não são estruturas formadas por partes estáticas do objeto, e sim organizações variadas de rabiscos espacialmente relacionados que expressam qualidades dinâmicas. "Seus gestos não recriam objetos, mas expressam emoções. Nessa fase, os desenhos são, antes de mais nada, narrações gráficas de estados emocionais" (Quaglia et al., 2015, p. 87)

Mais tarde, a estrutura formal do desenho evolui e substitui a representação das qualidades dinâmicas. As crianças deixam de retratar o que os objetos fazem para representar o que sabem sobre o objeto. Isso só é possível a partir do momento em que a criança é capaz de interiorizar o movimento sem precisar representá-lo no papel (Longobardi et al., 2012). A criança compreende que tanto a forma quanto o movimento representam o objeto, mas o momento em que a criança se encontra em seu desenvolvimento faz com que ela opte pela forma na tentativa de recriar um objeto.

\section{Esteticismo Prático}

Entre seis e 11 anos, as crianças se baseiam nas execuções formais e nas regras lógicas para avaliar seus desenhos. A fase de avaliar seus desenhos como "bom" ou "mau", "bonito" ou "feio" foi superada (Longobardi et al., 2012).

$\mathrm{Na}$ experiência com grupo de alunos da série primária de uma localidade à beira-mar, dois desenhos foram mostrados para as crianças. O primeiro desenho era de um barco situado na linha do horizonte, enquanto, no segundo desenho, o barco estava localizado um pouco abaixo da linha do horizonte. Justificou-se que o barco que estava na linha do horizonte encontrava-se mais longe da costa, enquanto o outro estava mais próximo.

Solicitou-se que as crianças decidissem se o desenho estava correto. $\mathrm{O}$ desenho que estava localizado abaixo da linha do horizonte e mais perto da costa foi considerado errado pelas crianças, porque, segundo elas, parecia que o barco estava afundando. A água estava sobre o barco, quando deveria estar sob ele (Quaglia, 1997). A conclusão a que chegaram os participantes se deve ao fato de que:

"A criança adota uma lógica gráfica na execução de seus desenhos que é válida apenas em um espaço bidimensional, por isso alguns fenômenos, típicos do desenho infantil, que o caracterizam e o tornam único e rico em exageros e originalidade, devem ser lidos como expressão de tal lógica" (Longobardi et al., 2012, p. 136).

Os critérios estéticos são individualizados e definidos com uma lógica aparente que avalia resultados imediatos e, com base nessa mesma lógica, definem os desenhos como certos e agradáveis ou errados e feios, conferindo a essa fase o título de Esteticismo Prático. Situação semelhante se observou quando se apresentou às crianças (de seis a 11 anos) um desenho de uma mãe com um bebê visível na barriga (o desenho apresentava transparência).

Após observar que as crianças haviam compreendido o desenho, outro desenho semelhante foi apresentado às crianças, mas dessa vez o feto não estava visível. As crianças foram informadas de que no segundo desenho também havia uma mãe com um bebê na barriga. Todos os participantes responderam que, no segundo desenho, a mulher não tinha um bebê na barriga. Disseram que a mulher estava gorda e, com base nisso, consideraram que o segundo desenho estava errado (Quaglia, 1997). "A transparência é um fenômeno que é causado pela falta de profundidade em um meio bidimensional que, se algo não for representado, ele não existe" (Quaglia et al., 2015, p. 88).

Nessa fase, a criança não concebe que, em uma folha de papel bidimensional, poderia haver algo que não apareça. Não há como esconder as coisas atrás das outras, pois no papel não haveria lugar para isso (Quaglia et al., 2015). Outra peculiaridade nos desenhos infantis é a representação canônica.

Em um experimento apresentaram a crianças de cinco a nove anos de idade duas canecas. Em uma delas a asa não era visível (sem representação canônica), na outra havia uma flor pintada em um dos lados claramente visível. Em seguida, solicitou-se que os participantes desenhassem o que estavam vendo. As crianças de sete anos desenharam a caneca com a asa, mas sem a flor. As crianças maiores desenharam a caneca com a flor e sem a asa. Isso implicaria dizer que as crianças mais novas se atêm aos detalhes estruturais que definem o objeto, mesmo que não estejam aparentes (Quaglia et al., 2015). Isso ocorre porque as crianças consideram os movimentos que um sujeito pode realizar com o objeto.

Na Perspectiva Dinâmica e Estética, a asa de uma caneca não só é um elemento determinante da forma do objeto, mas também é seu elemento dinâmico. Ou seja, o elemento que torna a caneca reconhecível por causa da ação que um sujeito pode realizar com ela. (Longobardi et al., 2012).

As crianças pequenas percebem os objetos com base no que pode ser feito com eles: uma caneca sem a asa sugere às crianças um movimento semelhante ao que se faz quando se utiliza um copo. Dessa forma, na Perspectiva Dinâmica e Estética, a representação canônica é também uma representação dinâmica dos objetos. A representação 
em que as ações (e não a informação) tornam a forma do objeto reconhecível é chamada de representação dinâmica. (Longobardi et al., 2001).

A visão frontal de casas e a visão lateral de animais, por exemplo, geralmente, expressam não só expressões estáticas, mas também expressões dinâmicas. Essas percepções apresentam o lado do objeto que favorece a compreensão do movimento que pode ser realizado com ele. Por exemplo: a porta de uma casa é frontal, a porta de um carro é lateral. (Longobardi et al., 2001).

\section{Esteticismo Convencional}

Nessa fase, o desenho se transforma e perde a peculiaridades do traçado infantil. Ao adquirirem profundidade, os objetos passam a se organizar dentro de um novo espaço tridimensional, projetado dentro do papel. O desenho se torna mais realista e reflete o desenvolvimento intelectual. Esse desenho é "como uma cópia da realidade e marca o fim da 'graficidade' infantil" (Quaglia et al., 2015, p. 89).

Enquanto o mundo interno do adolescente se torna cada vez mais complexo, a vida imaginativa se empobrece. Ao contrário da criança que tinha a necessidade de representar graficamente os objetos, os adolescentes experimentam mentalmente as qualidades desses objetos (Quaglia et al., 2015).
A variação existente no traçado infantil não é mais suficiente para que o adolescente expresse a complexidade de seu mundo interno, permeado por fortes emoções, angústias, conflitos e ideias. Diante dessa impossibilidade, o adolescente abandona o desenho e começa a buscar uma nova forma de expressão.

\section{Considerações Finais}

A Perspectiva Dinâmica e Estética apresenta uma nova forma de conceber o processo de desenvolvimento do desenho, especialmente no que tange à fase do rabisco expressivo que, de forma inovadora, pressupõe a expressão de estados emocionais já nos rabiscos iniciais, e não somente após o desenho esquemático. Nota-se, nessa nova abordagem, a integração funcional de aspectos biológicos, psicológicos e sociais na descrição de um processo fluido na evolução do desenho.

O corpo da criança se manifesta no gesto, e esse gesto revela o que a criança sente e, a depender de como essa produção será recebida pelo adulto, ela se sentirá acolhida ou não. $\mathrm{O}$ rabisco é mais que a consequência do gesto, não é motivado somente pelo prazer motor. É como se fosse um órgão do sentido que contribui para a inserção da criança e de seus sentimentos, angústias e fantasias no mundo.

\section{Referências}

Assao, T. Y., Westphal, M. F., Bógus, C. M., Lara, B. R., \& Cervato-Mancuso, A. M. (2014). School Feeding: What children's drawings reveal. Journal of Human Growth and Development, 24(1), 98-105. Recuperado de http://pepsic.bvsalud.org/scielo.php?script=sci_ arttext\&pid $=$ S0104-12822014000100015\&lng $=$ pt\&tlng $=$ en

Bombonato, G. A., \& Farago, A. C. (2016). As etapas do desenho infantil segundo autores contemporâneos. Cadernos de Educação: Ensino e Sociedade, 3(1), 171-195. Recuperado de http://unifafibe.com.br/revistasonline/arquivos/cadernodeeducacao/sumario/40/30042016104546.pdf

Broering, C. V., \& Crepaldi, M. A. (2014). Psychological preparation for surgery: verbal report of the drawing-story. Estudos de Psicologia (Campinas), 30(3), 367-374. doi: 10.1590/S0103-166X2013000300006

Campos, D. M. S. (1987). O teste do desenho como instrumento de diagnóstico da personalidade. Petrópolis, RJ: Editora Vozes.

Cox, M. (2012). Desenho da criança. São Paulo, SP: Martins Fontes.

Derdyk, E. (2015). Formas de pensar o desenho: Desenvolvimento do grafismo infantil. Porto Alegre, RS: Zoukk editora.

Federizzi, R. B., \& Cunha, R. (2015). Garatuja, evolução gráfica e letramento. Revista Práxis, 1(1), 88-98. Recuperado de http://www. fabemarau.edu.br/images/downloads/Revista_Cient\%C3\%ADfica/praxis_final.pdf\#page $=89$

Longobardi, C., Negro, A., Pagani, S., \& Quaglia, $\bar{R}$. (2001). Il disegno infantile. Una rilettura psicológica. Torino, Itália: UTET Librería.

Longobardi, C., Pasta, T., \& Quaglia, R. (2012). Manuale di disegno infantille: Vecchie e nuove prospettive in âmbito educativo e psicológico. Torino, Itália: UTET Libreria.

Longobardi, C., Quaglia, R., \& Iotti, N. O. (2015). Reconsidering the scribbling stage of drawing: A new perspective on toddlers' representational processes. Frontiers of Psychology, 6, 1-9. doi: 10.3389/fpsyg.2015.01227

Lopes, S. R. A. (2012). O uso do recurso gráfico como meio de interação e comunicação com crianças hospitalizadas. Em R. M. L. Affonso (Org.) Ludodiagnóstico: Investigação clínica através do brinquedo (pp. 200-206). Porto Alegre, RS: Artmed.

Lowenfeld, V. (1970). A criança e sua arte. São Paulo, SP: Mestre Jou.

Luquet, G. (1969). O desenho infantil. Barcelona, Espanha: Porto Civilização.

Méredieu, F. (2006). O desenho infantil. São Paulo, SP: Cultrix.

Oliveira, K. S., \& Wechsler, S. M. (2016). Indicadores de criatividade no desenho da figura humana. Psicologia: Ciência e Profissão, $36(1), 6-19$. doi: 10.1590/1982-3703001682014

Piaget, J. (1976). A equilibração das estruturas cognitivas. Rio de Janeiro, RJ: Zahar.

Quaglia R. (1997). Il disegno infantile nell'arte e nei test. Moncalvo, Asti, Itália: Sharón.

Quaglia R., \& Saglione G. (1976). Il disegno infantile. Giunti, Firenze, Itália: Nuove linee interpretative.

Quaglia, R., Longobardi, C., Iotti, N. O., \& Prino, L. E. (2015). A new theory on children's drawings: Analyzing the role of emotion and movement in graphical development. Infant Behavior \& Development, 39, 81-91. doi: 10.1016/j.infbeh.2015.02.009 
Schwarz, M. L., Herrmann, T. M., Torri, M. C., \& Goldberg, L. (2016). "Chuva, como te queremos!": Representações sociais da água através dos desenhos de crianças pertencentes a uma região rural semiárida do México. Ciência \& Educação, 22(3), 651-669. doi: 10.1590/1516731320160030007

Silva, A. F., Aguiar Jr. O., \& Belmiro, C. A. (2015). Imagens e desenhos infantis nos processos de construção de sentidos em uma sequência de ensino sobre ciclo da água. Ensaio Pesquisa em Educação em Ciências, 17(3), 607-632. doi: 10.1590/1983-21172015170304

Zerbato, A. P., \& Lacerda, C. B. F. (2015). Desenho infantil e aquisição de linguagem em crianças surdas: Um olhar histórico-cultural. Revista Brasileira de Educação Especial, 21(4), 427-442. doi: 10.1590/S1413-65382115000400008

\section{Sobre as autoras}

Evelyn de Oliveira é psicóloga, Gestalt-terapeuta, especialista em avaliação psicológica e doutoranda em Psicologia da Saúde pela Universidade Católica Dom Bosco.

Sonia Grubits é doutora em Saúde Mental pela Faculdade de Ciências Médicas da UNICAMP. Doutorado com status de pós-doutorado por Paris 8 Sorbonne, França. Pós-doutorado em Saúde Mental no Trabalho pela UNICAMP. Atualmente é orientadora técnica do Instituto de Psicologia Médica de Mato Grosso, professora e pesquisadora da UCDB. 